\title{
Can Squamous cell carcinoma affect young healthy adults? case report of oral squamous cell carcinoma of the tongue in 19-year-old female
}

\author{
Amal M Alohali ${ }^{1}$, Razan A Ababtain ${ }^{2}$ and Abdulaziz A Binahmed ${ }^{* 3}$ \\ ${ }^{1}$ King Saud Bin Abdulaziz University, Ministry of National Guard health affairs, Riyadh ,Saudi Arabia \\ ${ }^{2}$ King Abdulaziz medical city, Ministry of National Guard health affairs, Riyadh, Saudi Arabia \\ ${ }^{3}$ King Abdulaziz medical city, King Saud Bin Abdulaziz University, Ministry of National Guard health affairs, Riyadh, Saudi Arabia
}

\begin{abstract}
Squamous cell carcinoma is the most common malignancy in the oral cavity. However, it rarely occurs in patients younger than 40 years of age. In this article, we report a rare case of squamous cell carcinoma of the tongue in a healthy 19-year-old female patient. This report highlights the etiological factors, diagnosis and prognosis of this case with a brief literature review.
\end{abstract}

\section{Introduction}

Oral squamous cell carcinoma (SCC) is the most common oral cancer, accounting for more than $90 \%$ of malignant lesions [1,2]. Worldwide, SCC is the eighth most common cancer in incidence with various geographic distributions [1]. It typically occurs in older age $[3,4]$, during fifth - eighth decades of life [5]. In regard to the gender predominance, male are more affected by SSC $[2,3,5,6]$. The most commonly affected site is the tongue, with the preponderance to the posterior lateral border [3]. The lip and floor of the mouth are also common sites followed by soft palate, gingiva and buccal mucosa [2,7]. The epidemiology of SCC is greatly affected by the risk factors. Alcohol consumption, use of tobacco and betel quid chewing are considered major risk factors in older groups $[2,8]$.

In this article we report a rare incidence of SCC in a young healthy female. This emphasizes the importance of including malignancy in the differential diagnosis of suspicious lesions in young patients.

\section{Case report}

This is a 19-years-old healthy female that presented with a nonhealing ulcer for two months. Initially, the patient was seen in a private clinic and was prescribed antibiotics and analgesics with no improvement. The patient was then referred to the oral and maxillofacial surgery clinic in King Abdulaziz Medical City (KAMC) in Riyadh from her general dentist in the primary health care center. The patient had a negative history of tobacco and alcohol use. The patient had no family history of malignancy or of exposure to secondhand smoke. She had no history of systemic disease, previous trauma or extensive dental treatment except for orthodontic treatment. On examination, the patient had a painful ulcer on the left posterior side of the dorsum of the tongue measuring $3 \times 4 \mathrm{~cm}$ with irregular and indurated margins. The surrounding mucosa was erythematous with exophytic growth. (Figure 1) there was limitation in tongue movement with no difficulty in swallowing. Lymph nodes at level II on the left side were palpable.
A provisional diagnosis of traumatic ulcer was made. Differential diagnosis included traumatic ulcer, syphilis, and tuberculosis. Incisional biopsy was performed under general anesthesia with specimens from different sites of the lesion. The histopathology report shows infiltrating sheets of highly atypical squamous cells, consistent with moderately differentiated squamous cells carcinoma (Figure 2). In a view of this diagnosis, computed tomography (CT) was done for the face, abdomen and chest and showed an enhanced soft tissue mass measuring $3 \mathrm{x} 4 \mathrm{~cm}$ in the left tongue (Figure $3-\mathrm{A}$ ) pathological necrotic lymph node at level $2 \mathrm{~A}$ (Figure 3-B) and a small nodule measuring 1.3 $\mathrm{cm} \times 0.8 \mathrm{~cm}$ in the right breast. Lung and abdomen were clear with no nodules or masses. PET scan and head and neck MRI revealed a left hypermetabolic tongue lesion approaching the midline and extending to the floor of mouth, metastatic left neck level II A and level IB lymph nodes (Figure 4-A, B).
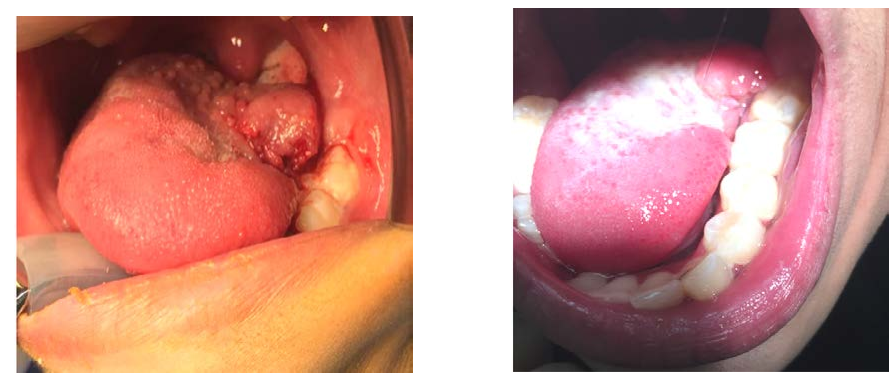

Figure 1. Ulcerative lesion on the left posterior side of the dorsum of the tongue.

Correspondence to: Abdulaziz A Binahmed, Consultant oral and maxillofacial surgery/head \& neck surgery, King Abdulaziz medical city, King Saud Bin Abdulaziz University, Ministry of National Guard health affairs, Riyadh, Saudi Arabia; Tel: 96612520088 Ext 14119; E-mail: azizbinahmed@mac.com

Key words: Oral cavity, squamous cell carcinoma, young adults

Received: January 04, 2017; Accepted: January 16, 2017; Published: January 19, 2017 


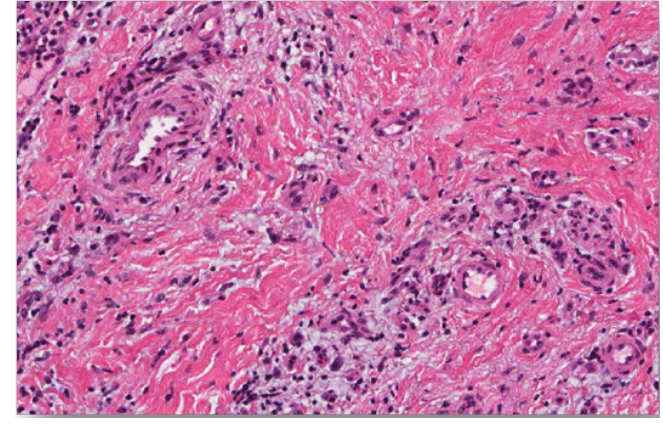

Figure 2. Excised tissue stained with $H \& E$ corresponding with moderately differentiated SCC
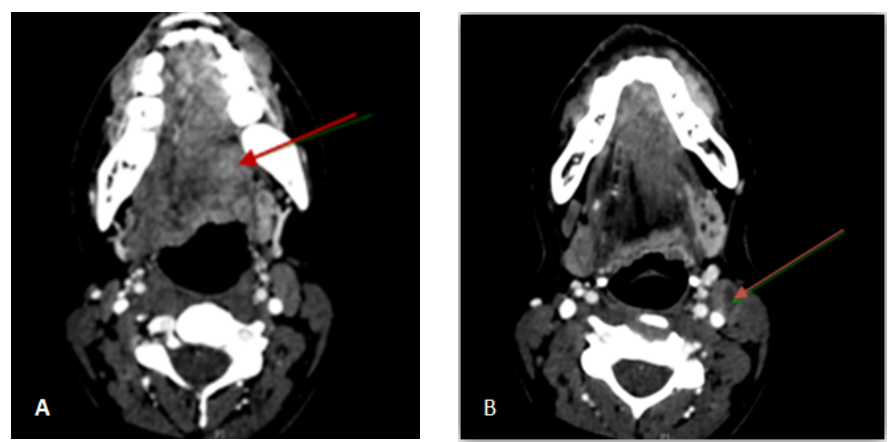

Figure 3. A. CT showing soft tissue mass involving the left tongue posteriorly with heterogeneous contrast enhancement. B. Left level 2 A pathological necrotic lymph node with peripheral enhancement.
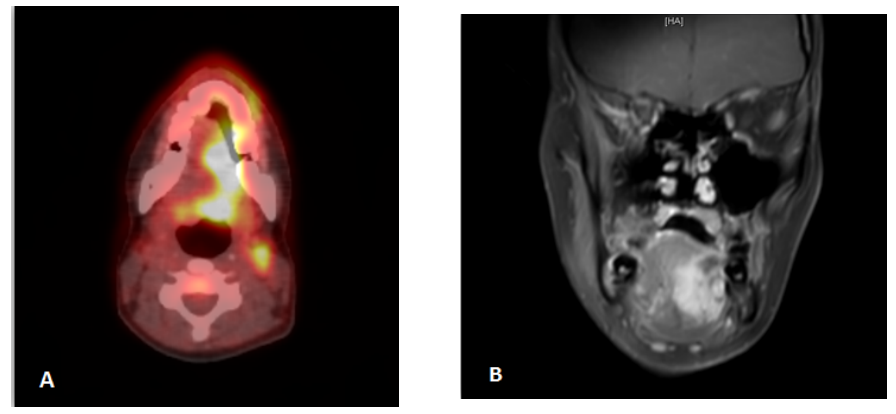

Figure 4. A. PET scan showing hypermetabolic lesion in left side of the tongue and two hypermetabolic lymph nodes at level of II A. B. MRI showing left tongue ulcerated mass extending to the left tongue base and left side of the mouth floor muscles.

Breast ultrasound showed a well-defined hypoechoic horizontallyoriented capsulated solid mass in the retroareolar region corresponding to the CT findings and consistent with a benign entity.

The staging of the tumor according to the TNM was estimated to be: T3N2bMx. Case was discussed in the head and neck tumor board meeting in king Abdulaziz medical city for management which consisted of surgical treatment first followed by concomitant chemotherapy and radiotherapy. The patient underwent surgery for tracheostomy, subtotal glossectomy, reconstruction with left radial forearm flap, bilateral neck dissection and marginal mandibulectomy. The final histopathology report showed all margins of the resection were free of tumor. Extensive lymphovascular and perineural invasion was identified. Left sublingual gland was positive for squamous cell carcinoma. Foci of tumor metastasis (ranging from $0.5 \mathrm{~cm}$ up to 1.5 $\mathrm{cm}$ ) into three lymph nodes out of seventy-three total bilateral neck dissection lymph nodes was identified. Attempts to do the Human Papilloma virus in-situ hybridization studies (HPV-ISH) were not successful due to the unavailability in our institution at the present time.

Following the surgical treatment, the patient was referred to the oncology department in KAMC for chemo- and radiotherapy. The patient received a radiation dose of $66 \mathrm{~Gy}$ in 33 fractions with chemotherapy of Cetuximab over a period of 6 weeks. At the end of the treatment, the patient developed grade III mucositis, grade II dermatitis and burning sensation in the skin over the chin. The patient also suffered from weight loss and nutritional deficiency.

\section{Discussion}

SCC is rare in young adults with a percentage of 1 to $6 \%$ [3]. Interestingly, in recent years there has been an increase in incidence worldwide. The percentage of SCC of the tongue in young adults increased from 3\% in 1973 to 6\% in 1993. In Saudi Arabia, Oral cancer appears to represent 4.3 to $17.8 \%$ of all registered cancers with a steady increase in incidence in the last decade [9].

In previous literature, when comparing SCC in young adults with groups over the age of 40, some differences have been described. Looking at the gender distribution, younger groups showed equal sex predilection, whereas the older patients showed higher incidence in males $[10,11]$. Both age groups have the same clinical presentation with no distinguishing features [3,5]. Several authors reported a more aggressive behavior of SCC in younger patients with poorer prognosis $[10,11]$.

The most common risk factors of SCC are alcohol and smoking; however this is a controversial topic in young adults. Some authors argue that these risks factors are not applicable in this age group for two reasons. First, the incidence of smoking and alcohol consumption in this group is low; secondly if present the exposure time is relatively short to cause a malignant transformation $[3,10,12]$. Other factors associated with SCC include viral infections caused by Human Papilloma virus (HPV) and Epstein-Barr viruses (EBV) [3,10].

Some authors suggest an association between SSC and immunodeficiency states in younger patients $[8,10]$. In this age group, there has been an association between SCC and genetic conditions such as Fanconi's anemia, xeroderma pigmentosum, keratitis, ichthyosis and deafness (KID) syndrome $[7,11]$.

In this article, we report a case of tongue SCC in a 19-year-old female with a negative history for smoking and alcohol consumption. Her past medical history and family history were not significant. The most elucidating factor for a justification of SCC in this patient was chronic trauma from her previous orthodontic treatment. However, previous studies failed to prove that trauma alone can cause malignant transformation [5]. The presence of a premalignant lesion or HPV association cannot be ruled out in this case.

According to previous studies, the tongue is the most common site of oral SCC in the young patients [13]. In 2000, Oliver et al reported 3 cases of oral SCC in the tongue, all affecting patients below the age of 30 . The first case reported a 26-year-old male medically free but presented with a sore area in the left side of his tongue. Diagnosis of SCC was confirmed with a biopsy and the patient underwent total excision only. The patient was followed for 5 years with no evidence of recurrence. The second case was a 24-year-old female that presented with a lump under her tongue with lymph node evolvement. Following surgical treatment, the patient received radiotherapy and remained disease free for 5 years. The last case reported a 20 -year-old female with ulcerative 
lesion in the lateral border of the tongue with lymph node involvement. Patient was treated with surgical resection and radiotherapy however she died 5.5 months later [14].

In this case, the patient underwent surgical treatment which consisted of subtotal glossectomy, reconstruction with left radial forearm flap, bilateral neck dissection and marginal mandibulectomy followed by concurrent radiotherapy and chemotherapy. The patient is under regular follow up with the oncology department and nutritional department.

\section{Conclusion}

Clinicians should include SCC in their differential diagnosis of suspicious lesions regardless of its rare occurrence in young patients. A non-healing lesion should be biopsied as early as possible, as the prognosis of SCC is affected by the early diagnosis.

\section{References}

1. Massano J, Regateiro FS, Januário G, Ferreira A (2006) Oral squamous cell carcinoma: review of prognostic and predictive factors. Oral Surg Oral Med Oral Pathol Oral Radiol Endod 102: 67-76. [Crossref]

2. Cabral LA, de Carvalho LF, Salgado JA, Brandão AA, Almeida JD (2010) Gingival squamous cell carcinoma: a case report. J Oral Maxillofac Res 1: 6. [Crossref]

3. Hirota S, Migliari D, Sugaya N (2006) Oral Squamous Cell Carcinoma in A young Patient Case Report and Literature Review. An bras dermatol 81: 251-254.

4. Chiang W, Yu Yen C, Yen Liu S (2005) Squamous cell carcinoma of the oral cavity in young patients. Chin J oral maxillofac surg 16: 8-15.
5. Randhawa T, Shameena P, Sudha S, Nair R (2008) Squamous cell carcinoma of tongue in a 19-year-old female. Indian J Cancer 45: 128-130. [Crossref]

6. Tettamanti L, Caprioglio A, Tecco S, Barello G, Macchi A, et al. (2012) Oral Squamous Cell Carcinoma in the paediatric patient: a literature review. Eur J Paediatr Dent 13: 35-40. [Crossref]

7. Binahmed A, Charles M, Campisi P, Forte V, Carmichael RP, et al. (2007) Primary squamous cell carcinoma of the maxillary alveolus in a 10-year-old girl. J Can Dent Assoc 73: 715-718. [Crossref]

8. Sankaranarayanan R, Mohideen MN, Nair MK, Padmanabhan TK (1989) Aetiology of oral cancer in patients less than or equal to 30 years of age. Br J Cancer 59: 439-440. [Crossref]

9. Idris A, Vani NV, Saleh S, Tubaigy F, Alharbi F, et al. (2016) Relative Frequency Of Oral Malignancies And Oral Precancer In The Biopsy Service Of Jazan Province, 20092014. Asian Pac J Cancer Prev 17: 519-525.

10. Llewellyn CD, Johnson NW, Warnakulasuriya KA (2001) Risk factors for squamous cell carcinoma of the oral cavity in young people--a comprehensive literature review. Oral Oncol 37: 401-418. [Crossref]

11. Sidell D, Nabili V, Lai C, Cheung G, Kirsch C, et al. (2009) Pediatric squamous cel carcinoma: Case report and literature review. Laryngoscope 119: 1538-1541. [Crossref]

12. Langerman A, Blair E (2009) Head and neck carcinoma in the young patient.

13. Kaur J, Singh A, Chopra R (2016) Unusual Presentation of Squamous Cell Carcinoma In Young Female Patient: A Case Report And Review Of Literature. J Oral Maxillofac Pathol 20: 163. [Crossref]

14. Oliver RJ, Dearing J, Hindle I (2000) Oral cancer in young adults: report of three case and review of the literature. Br Dent $J$ 188: 362-365. [Crossref]

Copyright: $@ 2017$ Alohali AM. This is an open-access article distributed under the terms of the Creative Commons Attribution License, which permits unrestricted use, distribution, and reproduction in any medium, provided the original author and source are credited. 